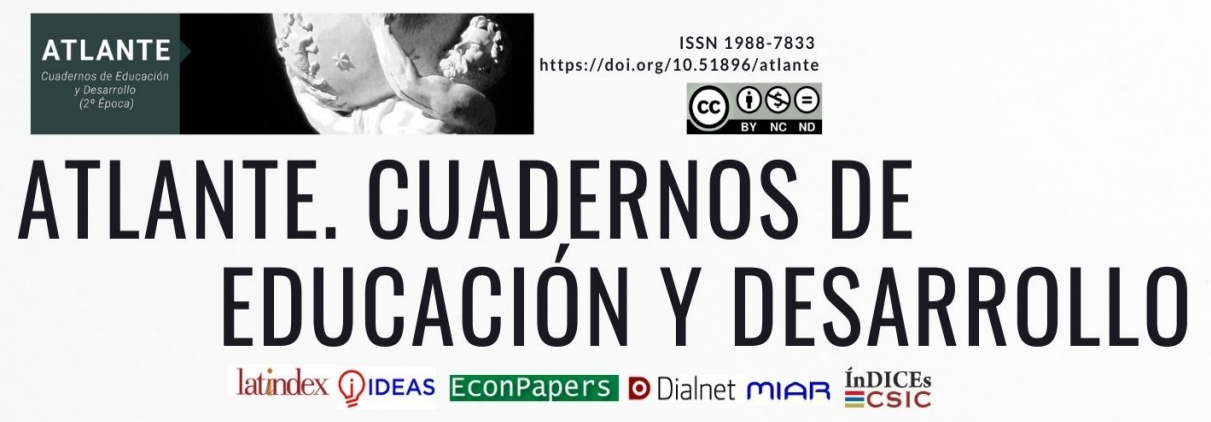

\title{
A TEMÁTICA FOTOSSÍNTESE PRESENTE EM LIVROS DIDÁTICOS DO ENSINO MÉDIO BRASILEIRO
}

\author{
Luana de Abreu Lemos ${ }^{1}$ \\ Universidade Estadual do Oeste do Paraná \\ luana.abreu.lemos@gmail.com \\ Lourdes Aparecida Della Justina ${ }^{2}$ \\ Universidade Estadual do Oeste do Paraná \\ lourdesjustina@gmail.com
}

Para citar este artículo puede utilizar el siguiente formato:

Luana de Abreu Lemos y Lourdes Aparecida Della Justina: "A temática fotossíntese presente em livros didáticos do ensino médio brasileiro", Revista Atlante: Cuadernos de Educación y Desarrollo (vol 13, № 3 marzo 2021, pp. 1-18). En línea:

https://www.eumed.net/es/revistas/atlante/2021-marzo/fotossintese-livros-didaticos

\begin{abstract}
Resumo
Os livros didáticos (LD) apresentam uma linguagem mais compreensível que a apresentada na comunidade científica devido a transformações que ocorrem por meio da transposição didática. Esse processo compreende reconstruções do conhecimento científico para o conhecimento apresentado no LD e estudado em sala de aula. $O$ objetivo do presente trabalho é levantar e analisar o conhecimento de fotossíntese em oito LD de biologia quanto às aproximações e aos distanciamentos devido ao processo de transposição didática. A pesquisa é de cunho qualitativo e os materiais analisados datam do ano de 1990 até 2013. As obras selecionadas estão disponíveis no Laboratório de Ensino de Biologia de uma universidade pública brasileira. A escolha dos livros ocorreu a partir da apresentação explícita do termo fotossíntese. Os resultados indicam que nos LD há o predomínio da abordagem do processo de fotossíntese relacionado ao sustento da vida heterotrófica em detrimento da autotrófica.
\end{abstract}

Palavras-chave: Ensino de Biologia, Livro didático, Transposição didática.

THE PHOTOSYNTHESIS THEME IN BRAZILIAN HIGH SCHOOL TEACHING BOOKS 


\begin{abstract}
Textbooks (TB) have a more understandable language than that presented in the scientific community, due to the transformations that occur through didactic transposition. This process comprises reconstructions of scientific knowledge in the knowledge presented in the TB and studied in the classroom. The objective of the present work is to raise and analyze the knowledge of photosynthesis in eight TB of biology regarding the approximations and distances due to the didactic transposition process. The research is of a qualitative nature and the analyzed materials date from the year 1990 to 2013, being selected the works available in the Biology Teaching Laboratory of a Brazilian public university. The choice of books was based on the explicit presentation of the term photosynthesis. And the results indicate that in TB there is a predominance of the approach of the photosynthesis process related to sustaining heterotrophic life to the detriment of autotrophic.
\end{abstract}

Keywords: Biology teaching, Textbook, Didactic transposition.

\title{
LA TEMÁTICA FOTOSÍNTESIS PRESENTE EN LIBROS DIDÁCTICOS DE LA ENSEÑANZA SECUNDARIA BRASILEÑA
}

\section{Resumen:}

Los libros didácticos (LD) presentan un lenguaje más comprensible que el presentado en la comunidad científica debido a las transformaciones que ocurren por medio de la transposición didáctica. Ese proceso comprende reconstrucciones del conocimiento científico para el conocimiento presentado en los LD y estudiado en aula. El objetivo del presente trabajo es buscar y analisar el conocimiento de fotosíntesis en ocho LD de biología con respecto a las aproximaciones y a los distanciamientos debido al proceso de transposición didáctica. La investigación es de carácter cualitativo y los materiales analizados son del año de 1990 hasta 2013. Las obras seleccionadas están disponibles en el Laboratorio de Enseñanza de Biología de una universidad pública brasileña. La selección de los libros ocurrió a partir de la presentación explícita del término fotosíntesis. Los resultados indican que en los LD hay el predominio del abordaje del proceso de fotosíntesis relacionado al sustento de la vida heterotrófica en detrimento de la autotrófica.

Palabras clave: Enseñanza de Biología, Libro didáctico, Transposición didáctica.

\section{Introdução}

A fotossíntese tem função vital nos vegetais, ou seja, possibilita a nutrição autotrófica. A compreensão desse fenômeno biológico, pelos alunos da educação básica, mobiliza diferentes áreas do conhecimento científico, como ecologia, anatomia e fisiologia vegetal, além das áreas da física e da química, devido às diversas conversões de energia envolvidas no processo fotossintético. Nesse sentido, destaca-se a relevância de compreensão adequada desse fenômeno para entendimento do fluxo de energia na teia alimentar e até mesmo da dinâmica da vida em nosso planeta. 
Entretanto, para que realmente ocorra o processo de ensino e aprendizagem desse fenômeno biológico, o conhecimento científico não deve ser apresentado ao aluno como os cientistas o disseminam para a comunidade científica. É necessário que esse conhecimento passe por um processo chamado de transposição didática, que, conforme Chevallard (1991), são transformações que ocorrem no conhecimento de modo a facilitar a sua compreensão, ou seja, que o elemento de saber possa ser compreendido.

Um conjunto de conhecimentos desenvolvidos ao longo de certo tempo pode se denominar de "saber". Diante disso, temos a escola como um local de construção de saberes, bem como reorganização e reconstrução. É nela que grande quantidade de conhecimento é disponibilizada à sociedade (Gomes et al, 2014).

O conhecimento produzido pela academia, denominado "saber sábio", é restrito e especializado, um saber que precisa ser compreendido e decodificado para ser ensinado (Melzer, 2012). As transformações que ocorrem no saber sábio geram o saber a ensinar, o qual é redirecionado de acordo com a sociedade em que está inserido para que, no conteúdo conceitual, possa ser relacionado a questões sociais e políticas da comunidade escolar em questão. Quando fala-se sobre ação, sobre como o processo aconteceria em sala de aula, dizemos sobre o saber ensinado, ele é aquilo que se entende (Gomes; Gomes; Terán, 2014). Essas transformações ao redor do conhecimento científico auxiliam o aluno a compreender melhor o saber ensinado.

Neste artigo, apresenta-se os resultados de um estudo que buscou evidenciar aproximações e distanciamentos presentes no conhecimento acerca da fotossíntese entre o saber sábio e o saber a ensinar.

\section{O tema fotossíntese e seu ensino}

Relatos de pesquisas envolvendo o ensino da fotossíntese têm sido divulgados e apontam dificuldades nesse processo de aprendizado. As pesquisas apontam que há uma divergência entre o que os alunos entendem por fotossíntese e o conceito adotado pela comunidade científica. As concepções diferenciadas do conhecimento atualmente considerado adequado são apresentadas tanto por alunos como por professores. Essas ideias se constituem em obstáculos epistemológicos para a compreensão da importância da fotossíntese como um processo de síntese de alimentos (Souza; Almeida, 2002). Tendo em vista que os livros didáticos são a principal fonte de informações na educação básica (Rodrigues; Justina; Meglhioratti, 2011; Santos, Shneider, Justina, 2019), cabem estudos analíticos sobre qual modo o tema fotossíntese tem sido abordado como conhecimento científico e transposto para esse recurso didático ao longo dos anos.

Tratando-se dos principais estudos relacionados ao processo de fotossíntese ao longo da história, destaca-se o autor Jan Ingenhousz que, em 1796, propôs a ideia de que as plantas utilizavam apenas o carbono presente na molécula de gás carbônicoliberando, assim, o oxigênio na atmosfera. Em 1931, Cornelis Bernardus Van Niel percebeu em um de seus estudos com algas fotossintetizantes que essas não liberavam oxigênio e sim glóbulos de enxofre. Após esses resultados, Niel propôs que não apenas essas algas, mas as demais plantas realizariam uma quebra da molécula de água, logo o oxigênio liberado pertencia a essa, e não ao gás carbônico como se 
acreditava. Essa suposição teve mais foco após os estudos de Hill em 1937, pois, a partir disso, foi possível constatar que plantas produziram oxigênio na ausência de gás carbônico, essas especulações foram corroboradas por meio de experimentos realizados em 1941 (Almeida, 2005).

A fotossíntese é um processo que garante a fonte primária de energia para todos os seres vivos de um ecossistema, ou seja, ela promove o equilíbrio da cadeia alimentar. Assim, uma ideia a ser construída pelos estudantes de biologia é a de que a vida não está em constante equilíbrio. É importante que os alunos identifiquem que cada ser vivo supre suas necessidades alimentares de um modo diferente, permitindo que ocorra uma rede de interações entre eles (Brasil, 2002).

Alguns conteúdos, além de apresentarem certo grau de complexidade, como o de fotossíntese, trazem um obstáculo na compreensão do conceito devido à nomenclatura. A palavra fotossíntese, por exemplo, quer dizer "síntese de luz", mas o processo da fotossíntese resulta na conversão da energia solar em energia química, logo muitos alunos podem ter dificuldades no processo de compreensão se pensarem apenas na nomeação do conceito.

Alunos entrevistados em estudos anteriores conceituam o processo de fotossíntese de acordo com aquilo que ouvem no decorrer de suas histórias, apresentando conceitos aleatórios no intuito de definir a fotossíntese por meio de uma fragmentação do real conteúdo. Exemplo disso seria quando eles relacionam a fotossíntese a um processo que transforma o gás carbônico em oxigênio (Souza; Almeida, 2002).

Visto a relevância dos LD para muitos professores e alunos, em várias discussões sobre as obras destacam-se os erros conceituais e de linguagem - apresentados na forma de figuras e esquemas. Portanto, para que possa superar tais problemas, o professor deve analisar previamente o conteúdo do material a fim de aproximar a linguagem científica presente nos LD à linguagem cotidiana dos alunos, de modo a evitar possíveis equívocos durante suas aulas (Martins, 2006).

Para Bachelard (1996), o conhecimento científico é construído ao longo da história por meio da constante análise de erros anteriores. Diante disso, destaca-se a importância da análise dos LD com o intuito de ajudar na melhoria de novos materiais e, consequentemente, no processo de ensino e aprendizagem.

Nesse contexto de transposição didática, no qual vemos um conceito como um produto da academia sofrer diversas modificações ao longo do tempopara se adequar a um ambiente escolar, vale ressaltar o conceito de fotossíntese, assim como as principais contribuições decientistas responsáveis pela construção desse conhecimento ao longo dos anos.

\section{Procedimentos Metodológicos}

No total, foram analisados e escolhidos 8 livros (quadro 1) dentre os materiais existentes no Laboratório de Ensino de Biologia da Universidade Estadual do Oeste do Paraná/Unioeste. Os critérios para escolha foram: se o livro apresenta o conceito de fotossíntese e está datado entre os anos de 1990 a 2013. 


\section{Quadro 1-}

Relação dos livros analisados

\begin{tabular}{|c|c|c|c|c|}
\hline $\begin{array}{l}\text { Título do Livro/ } \\
\text { Ano de publicação }\end{array}$ & gla $\mathrm{Si}$ & Autor (es) & Editora & idade \\
\hline $\begin{array}{c}\text { Curso básico de } \\
\text { biologia- } 1 \text { Células e } \\
\text { tecidos/ } 1991\end{array}$ & L1 - 1991 & $\begin{array}{l}\text { AMABIS, J. M.; } \\
\text { MARTHO, G. R. }\end{array}$ & $\begin{array}{c}\text { Editora } \\
\text { Moderna Ltda. }\end{array}$ & $\begin{array}{l}\text { São } \\
\text { Paulo }\end{array}$ \\
\hline $\begin{array}{c}\text { Biologia Hoje-Volume } \\
1 / 1993\end{array}$ & L2 - 1993 & $\begin{array}{c}\text { LINHARES, S.; } \\
\text { GEWANDSZNAJDE,R, } \\
\text { F. }\end{array}$ & Editora Ática & $\begin{array}{c}\text { São } \\
\text { Paulo }\end{array}$ \\
\hline $\begin{array}{c}\text { Bio Volume Único/ } \\
1998\end{array}$ & L3 - 1998 & $\begin{array}{l}\text { LOPES, S. G. B. } \\
\text { Carvalho }\end{array}$ & Editora Saraiva & $\begin{array}{l}\text { São } \\
\text { Paulo }\end{array}$ \\
\hline Biologia/1999 & L4 - 1999 & SOARES, J. L. & $\begin{array}{l}\text { Editora } \\
\text { Scipione }\end{array}$ & $\begin{array}{c}\text { São } \\
\text { Paulo }\end{array}$ \\
\hline $\begin{array}{c}\text { Fundamentos de } \\
\text { Biologia Moderna/ } \\
2001\end{array}$ & L5 - 2001 & $\begin{array}{l}\text { AMABIS, J. M.; } \\
\text { MARTHO, G. R. }\end{array}$ & $\begin{array}{c}\text { Editora } \\
\text { Moderna Ltda. }\end{array}$ & $\begin{array}{l}\text { São } \\
\text { Paulo }\end{array}$ \\
\hline $\begin{array}{c}\text { Fundamentos da } \\
\text { Biologia Moderna/2003 }\end{array}$ & L6 - 2003 & $\begin{array}{l}\text { AMABIS, J. M.; } \\
\text { MARTHO, G. R. }\end{array}$ & Moderna & $\begin{array}{l}\text { São } \\
\text { Paulo }\end{array}$ \\
\hline Biologia/2009 & L7 - 2009 & $\begin{array}{c}\text { LINHARES, S.; } \\
\text { GEWANDSZNAJDER, } \\
\text { F. }\end{array}$ & Editora Ática & $\begin{array}{c}\text { São } \\
\text { Paulo }\end{array}$ \\
\hline $\begin{array}{c}\text { Biologia em contexto- } \\
\text { Volume 1/ } 2013\end{array}$ & L8 - 2013 & $\begin{array}{l}\text { AMABIS, J. M.; } \\
\text { MARTHO, G. R. }\end{array}$ & Moderna & $\begin{array}{c}\text { São } \\
\text { Paulo }\end{array}$ \\
\hline
\end{tabular}

A pesquisa teve caráter qualitativo, ou seja, é dependente de todo o processo investigativorelacionando à perspectiva histórica de cada época (Flick, 2004). Para que a análise dos LD ocorresse, utilizou-se uma adaptação de um roteiro criado por Neves em 2009, embasado nos elementos de transposição didática desenvolvido por Chevallard (1991). O roteiro adaptado contém as seguintes categorias: descontextualização, despersonalização, relação novo/antigo, criações didáticas, publicidade do saber, desincretização, programabilidade de aquisição do saber e envelhecimento moral/biológico. 
A despersonalização do saber refere-se ao modo em que ele é apresentado, com objetivo de torná-lo publicável em qualquer meio de comunicação sem que sejam informados os seus criadores. Desincretização trata de como ocorreu a divisão dos conteúdos no livro, em capítulos e/ou unidades. Descontextualizar consiste em retirar o conteúdo do seu contexto original e relacioná-lo à problemática atual, contextualizando com situações vivenciadas pelos alunos. A publicidade do saber ocorre quando o livro apresenta a importância/finalidade de estudar determinado conteúdo ou a maneira como se desenvolve ao longo do livro.

As criações didáticas são elaboradas com o objetivo de auxiliar na compreensão de um conceito, são apresentadas como figuras, esquemas e outras formas. A Relação antigo/novo analisa como o livro organizou os saberes ao longo do tempo, se apresentou informações aceitas em determinada época. O Envelhecimento moral/biológico trata de como o livro didático atualiza seus conteúdos, se os assuntos foram renovados ao longo da história e acompanham os avanços e se o livro apresenta a importância do conteúdo para a vida do aluno.

\section{Resultados e Discussão}

Em relação à característica de despersonalização, o quadro a seguir (quadro 2) apresenta dados da análise dos livros quanto à explicitação ou não dos pesquisadores que participaram da construção do conhecimento acerca da fotossíntese.

\section{Quadro 2 -}

Análise dos autores (não) citados nos livros didáticos.

\begin{tabular}{|c|c|}
\hline Livro & Descrição \\
\hline $\mathrm{L} 1-1991$ & $\begin{array}{l}\text { O livro cita a reação de Hill ou fotólise da água. Nela ocorre a } \\
\text { quebra das moléculas de água. }\end{array}$ \\
\hline L2 - 1993 & Não cita nenhum dos principais autores. \\
\hline L3 - 1998 & $\begin{array}{l}\text { O livro cita apenas que Hill, em 1937, evidenciou que o } \\
\text { oxigênio desprendido provém da água e não do dióxido de carbono } \\
\text { como anteriormente se acreditava. }\end{array}$ \\
\hline L4- 1999 & $\begin{array}{l}\text { O livro cita Elgelmann, responsável por salientar os } \\
\text { comprimentos de onda luminosa responsáveis pela ação da } \\
\text { fotossíntese por meio de um experimento utilizando bactérias em } \\
\text { suspensão. Além disso, não há a menção de outro autor, apenas o } \\
\text { destaque de que a "fase luminosa" pode ser chamada de fase de Hill. }\end{array}$ \\
\hline L5 - 2001 & Não cita nenhum autor. \\
\hline $\mathrm{L} 6-2003$ & Não cita nenhum autor. \\
\hline L7 - 2009 & $\begin{array}{l}\text { O livro cita os estudos realizados na década de } 1940 \text { por } \\
\text { Melvin Calvin, os quais puderam confirmar a existência de uma fase } \\
\text { bioquímica, ou Ciclo de Calvin. Embora não cite os estudos e autores } \\
\text { relacionados, o livro menciona a formação do NADPH e relata sobre } \\
\text { os ciclos cíclicos e acíclicos. }\end{array}$ \\
\hline
\end{tabular}



plantas tiram do solo apenas pequenas quantidades de substâncias minerais que não correspondem diretamente ao crescimento vegetal, o que atribui o crescimento à água.

Os livros L2 - 1993 e L6 - 2003 não citam nenhum autor. Os L1 - 1991, L3 - 1998 e L4 - 1999 citam os estudos realizados por Hill, nos quais ele conclui que o oxigênio desprovido provém da fotólise da água e não do gás carbônico como se acreditava anteriormente. O livro de 1999 cita também Elgelmann, o responsável por salientar os comprimentos de ondas luminosas utilizados no processo de fotossíntese. Somente em 2009, o L7 - 2009 passa a citar os estudos realizados por Melvin Calvin, os quais confirmaram a existência de uma fase bioquímica, que mais adiante foi denominada por ciclo de Calvin. Já o livro L8 - 2013 cita os estudos realizados por Van Helmont que relacionaram o crescimento vegetal à água e somente aos nutrientes do solo como se acreditava.

Em relação ao ensino aprendizagem, acredita-se ser indispensável o conhecimento histórico para que o aluno compreenda que tudo aquilo que ele aprende em sala de aula foi construído, dessa forma faz-se necessária a citação dos autores ou dos estudos realizados durante esse período. Por meio da análise do fato de que a origem do oxigênio liberado durante a fotossíntese ainda é uma das mais divergentes explicadas pelos alunos, abordar os estudos realizados por Hill e Niel, os quais detalham que o oxigênio liberado provém da molécula de água e não do gás carbônico como se acreditava, são extremamente indispensáveis (Carvalho, 1992).

No caso da desincretização, no quadro 3 , demonstra-se como o conceito de fotossíntese é apresentado no livro, se isso ocorre em apenas um capítulo e se esse é específico apenas do tema ou se o conceito está localizado em um tópico ou subtítulo do livro.

\section{Quadro 3 -}

Análise da distribuição dos conteúdos no livro didático.

\begin{tabular}{|c|c|}
\hline Livro & Descrição \\
\hline L1-1991 & \multicolumn{1}{c|}{ O conteúdo é abordado apenas no capítulo "Alguns aspectos do } \\
& \begin{tabular}{l} 
metabolismo celular" e apresenta diversos tópicos, são eles: A energia envolvida \\
nas reações químicas; A fermentação como processo de obtenção de energia; A \\
respiração celular; A fotossíntese, o processo de produção de glicose; O papel \\
da enzima no metabolismo celular; e A origem da diversidade das enzimas. Vale \\
ressaltar que os tópicos supracitados estão inseridos com outros conteúdos do \\
capítulo em questão. \\
\hline L2-1993 livro não apresenta um capítulo específico. Há o conceito de \\
fotossíntese dentro da unidade "Citologia" do capítulo "Os cloroplastos e a \\
fotossíntese", nos subtítulos "O mecanismo da fotossíntese", "As etapas a \\
fotossíntese" e "A velocidade da fotossíntese". No mesmo capítulo, há os
\end{tabular} \\
\hline
\end{tabular}




\begin{tabular}{|c|c|}
\hline & conceitos de quimiossíntese e o processo de fotossíntese em procariotos. \\
\hline L3 - 1998 & $\begin{array}{l}\text { O conteúdo de fotossíntese é abordado na unidade Citologia, no capítulo } \\
\text { Metabolismo Energético da Célula I: Fotossíntese e Quimiossíntese, o qual é } \\
\text { específico. }\end{array}$ \\
\hline L4 - 1999 & $\begin{array}{l}\text { O livro é dividido em pequenas unidades, sem apresentar divisões de } \\
\text { capítulos. O conteúdo abordado na unidade é o "Consumo de energia pelo } \\
\text { organismo e renovação contínua da matéria". Destaca-se que há uma } \\
\text { abordagem mais detalhada na subunidade "A fotossíntese - produção de matéria } \\
\text { orgânica com a energia da luz", a qual apresenta uma segunda divisão: Fase } \\
\text { luminosa da fotossíntese, fase escura da fotossíntese, comentário gerais sobre a } \\
\text { fotossíntese, a demonstração prática da fotossíntese e a medida da fotossíntese. }\end{array}$ \\
\hline L5 - 2001 & $\begin{array}{l}\text { Não apresenta um capítulo específico, porém o tema é trabalhado } \\
\text { diversas vezes no livro. O conteúdo é abordado no capítulo "Breve história das } \\
\text { origens"; no capítulo "Energia e matéria na biosfera", com subtítulo "Seres } \\
\text { Autotróficos"; e no capítulo "Fisiologia das plantas Angiospermas", dentro de um } \\
\text { subtítulo chamado "Fisiologia da folha" o qual apresenta o tópico "Fotossíntese e } \\
\text { produção da seiva elaborada". }\end{array}$ \\
\hline L6 - 2003 & $\begin{array}{l}\text { Aborda brevemente sobre fotossíntese na unidade "O reino planta" no } \\
\text { capítulo Fisiologia das plantas Angiospermas". O tema é abordado mais } \\
\text { amplamente no capítulo "Envoltórios celulares e organização do citoplasma" no } \\
\text { subtítulo "Funções do cloroplasto: fotossíntese". Portanto, não apresenta um } \\
\text { capítulo específico do assunto. }\end{array}$ \\
\hline L7 - 2009 & $\begin{array}{l}\text { O conteúdo é abordado na unidade de Citologia no capítulo } \\
\text { "Cloroplastos e Fotossíntese". Não há outro conteúdo na unidade. }\end{array}$ \\
\hline L8 - 2013 & $\begin{array}{l}\text { O conteúdo é abordado no módulo denominado "Metabolismo energético } \\
\text { e reprodução celular", o assunto surge no capítulo: "Processos energéticos } \\
\text { celulares". O conteúdo de fotossíntese é abordado nos subtítulos a seguir: } \\
\text { "Luzes da fotossíntese", "Energia para a vida" e "O processo da fotossíntese". } \\
\text { Logo, o capítulo não é específico, pois aborda outros conteúdos relacionados } \\
\text { aos processos energéticos celulares, como a fermentação e respiração celular. }\end{array}$ \\
\hline
\end{tabular}

Em relação à distribuição dos conteúdos, especificamente do conteúdo de fotossíntese, em geral, os livros abordam os temas em capítulos subdivididos em diversos temas introdutórios e até complementares ao conceito de fotossíntese. O L7 - 2009 apresenta um capítulo específico o qual aborda o tema fotossíntese. Já o L7 - 2003, além de não apresentar um capítulo específico para o conceito de fotossíntese, aborda o tema em mais de um capítulo do livro.

No quadro 4, aborda-se a descontextualização. Na coluna "a" se o livro abordou ou não o estudo desenvolvido ao longo dos anos para se chegar ao conceito de fotossíntese aceito no período; e na coluna "b" se esse conceito contextualiza com a realidade do aluno. 


\section{Quadro 4 -}

Análise da descontextualização.

\begin{tabular}{|c|c|}
\hline Livro & III (a) \\
\hline $1-$ & $\begin{array}{l}\text { Sim, destaca apenas a reação de Não, o livro relata simplesmente } \\
\text { Hill, a qual, por meio da quebra dascomo se dá o processo sem relacioná-lo } \\
\text { moléculas de água, é formada por seisao cotidiano dos alunos. } \\
\text { moléculas de oxigênio. }\end{array}$ \\
\hline $2-1$ & $\begin{array}{l}\text { Embora o livro apresente as Apresenta o conteúdo de maneira } \\
\text { expressões "fase luminosa" e "escura"sintetizada, sem remetê-lo à realidade do } \\
\text { para representar as etapas fotoquímica ealuno. } \\
\text { bioquímica, traz o novo conceito. Não } \\
\text { abordanenhum dos estudos } \\
\text { desenvolvidos ao longo dos anos. }\end{array}$ \\
\hline $3-$ & $\begin{array}{l}\text { Não aborda os estudos } \text { O livro traz alguns experimentos } \\
\text { desenvolvidos ao longo dos anos. Trazrelacionados à liberação do oxigênio, à } \\
\text { as expressões "reação de claro" einfluência da luz no processo e, também, à } \\
\text { "escuro" para representar as etapaspresença do amido em alimentos, como a } \\
\text { fotoquímica e bioquímica. }\end{array}$ \\
\hline $4-1999$ & $\begin{array}{l}\text { Não aborda os estudos } \quad \text { Expõe o conteúdo de maneira } \\
\text { desenvolvidos ao longo dos anos. } \\
\\
\\
\text { clara e cita sua importância para os } \\
\text { organismos, porém sem remeter } \\
\text { diretamente à realidade do aluno. }\end{array}$ \\
\hline $5-2$ & $\begin{array}{l}\text { Não aborda os estudos } \begin{array}{l}\text { Apenas expõe brevemente } \\
\text { desenvolvidos ao longo dos anos. } \\
\text { conceito, sem relacioná-lo à realidade do } \\
\text { aluno. }\end{array} \\
\end{array}$ \\
\hline$\overline{-2}$ & $\begin{array}{l}\text { Não aborda os estudos } \quad \text { Não relaciona } \\
\text { desenvolvidos ao longo dos anos. }\end{array}$ \\
\hline $7-2$ & $\begin{array}{l}\text { Apenas aborda a origem do Apenas cita que os seres } \\
\text { nome da fase bioquímica da fotossíntese,heterotróficos dependem da fotossíntese } \\
\text { a qual pode ser chamada, desde 1940, depara sua nutrição seja direta ou } \\
\text { Ciclo de Calvin em homenagem aoindiretamente. } \\
\text { cientista responsável Melvin Calvin. }\end{array}$ \\
\hline 3 & $\begin{array}{l}\text { O Livro cita Van Helmont, no Sim, o livro apresenta um quadro } \\
\text { século XII, como suas evidências dade curiosidades denominado "A } \\
\text { presença de gás carbônico durante aimportância do assunto" (fotossíntese), e } \\
\text { fotossíntese. Relata também que aaborda o fato de que os seres dividem } \\
\text { origem do oxigênio liberado pelouma mesma "moeda energética"- ATP. Há } \\
\text { processo sucede da quebra daso conceito de fotossíntese principalmente } \\
\text { moléculas de água (fotolise da água). como um processo de transferência de }\end{array}$ \\
\hline
\end{tabular}




\section{energia do qual depende a vida humana}

Apenas os livros L1 - 1991, L7 - 2009 e L8 - 2013 citam alguns dos estudos que contribuíram para o desenvolvimento do conceito de fotossíntese ao longo dos anos. Os demais livros apenas apresentaram o conceito de fotossíntese atual. Dentre os livros analisados, o L3 - 1998 não remeteu o conteúdo à realidade do aluno, porém trouxe alguns experimentos que, se mediados pelo professor, poderiam ser uma ferramenta com essa finalidade. O L8 - 2013 foi o único livro que relacionou o conceito de fotossíntese à realidade dos alunos, ainda que de forma breve e isolada. Os demais livros não relacionaram o conceito à realidade dos alunos.

A publicidade do saber, analisada no quadro 5 , mostra se o livro apresentou ou não a importância desse processo para a compreensão das relações entre plantas e animais.

\section{Quadro 5 -}

Análise da importância/finalidade do conceito de fotossíntese nos livros didáticos.

\begin{tabular}{|c|c|c|}
\hline Livro & Não & Descrição \\
\hline L8 - 1991 & $\mathrm{X}$ & $\begin{array}{l}\text { Relata que o processo de fotossíntese é a via pela qual os } \\
\text { demais indivíduos obtêm energia e matéria-prima para suas } \\
\text { manutenções. }\end{array}$ \\
\hline L9 - 1993 & $\bar{X}$ & $\begin{array}{l}\text { Apresenta os vegetais como seres fundamentais para a } \\
\text { vida na Terra, e destaca que todos os seres heterotróficos } \\
\text { dependem deles para conseguir alimento, porque é a partir da } \\
\text { fotossíntese que os vegetais produzem matéria orgânica que os } \\
\text { outros indivíduos necessitam para sobreviverem. Relata também a } \\
\text { importância comercial dos vegetais para o homem. }\end{array}$ \\
\hline L10 -1998 & $\bar{X}$ & $\begin{array}{l}\text { Relata que os seres autótrofos são considerados } \\
\text { produtores, pois sintetizam a própria matéria enquanto os seres } \\
\text { heterótrofos precisam retirar seus alimentos de outros seres vivos, } \\
\text { por isso são chamados consumidores. }\end{array}$ \\
\hline L11 -1999 & $\bar{X}$ & $\begin{array}{l}\text { Aborda a fotossíntese como fonte inicial geradora de } \\
\text { matéria orgânica na natureza, um ponto de partida da cadeia } \\
\text { alimentar em todos os ecossistemas. E que o oxigênio liberado } \\
\text { nesse processo é um dos produtos de maior relevância na vida } \\
\text { dos seres da biosfera. }\end{array}$ \\
\hline $\mathrm{L} 12-2001$ & $\mathrm{X}$ & $\begin{array}{l}\text { O livro destaca de maneira breve o fato dos seres } \\
\text { fotossintetizantes possibilitarem a expansão dos seres } \\
\text { heterotróficos, pois dependem do oxigênio, um dos resultados da } \\
\text { fotossíntese. Cita também que os seres heterotróficos incorporam } \\
\text { produtos diretos ou indiretamente oriundos da fotossíntese. }\end{array}$ \\
\hline L13 - 2003 & $\mathrm{X}$ & Apenas destaca que praticamente todos os seres \\
\hline
\end{tabular}




\begin{tabular}{|c|c|c|}
\hline L14-2009 & $\begin{array}{l}\text { heterotróficos são dependentes da fotossíntese para obtenção de } \\
\text { alimento. }\end{array}$ \\
\hline L15-2013 & X & $\begin{array}{l}\text { Cita, de maneira sucinta, que a fotossíntese é processo } \\
\text { fundamental para a nutrição dos seres heterotróficos. }\end{array}$ \\
\hline & $\begin{array}{l}\text { O livro descreve que todos os seres dependem direta ou } \\
\text { indiretamente da energia luminosa, e que os seres } \\
\text { fotossintetizantes são os maiores especialistas na área energética. } \\
\text { A partir de uma energia luminosa, ocorre uma conversão em } \\
\text { energia química a qual supre as necessidades de praticamente } \\
\text { todos os seres vivos do planeta. }\end{array}$ \\
\hline
\end{tabular}

No geral, todos os livros analisados apresentaram a importância do processo de fotossíntese. Os livros trouxeram apenas a importância da fotossíntese para a nutrição dos seres heterotróficos. $O$ de 2013, além de apresentar essa importância, detalhou esse processo.

Devemos lembrar que a fotossíntese foi de suma importância para o sucesso dos seres heterotróficos, masacredita-se que os LD possuem o objetivo de evidenciar a sua importância no que se refere à fisiologia dos seres autotróficos, o que aborda com maior ênfase as necessidades desses seres. (Brasil, 2002).

No caso das criações didáticas, o quadro 6 mostra se os livros apresentam ou não algum tipo de criação didática, seguida de sua descrição.

\section{Quadro 6 -}

Análise das criações didáticas

\begin{tabular}{|c|c|c|}
\hline \multirow[t]{2}{*}{ Livro } & Sim & Descrição \\
\hline & Não & \\
\hline L1 - 1991 & $X$ & $\begin{array}{l}\text { A obra traz algumas fórmulas e reações que facilitam a } \\
\text { compreensão de determinados assuntos. Há, nas laterais das } \\
\text { páginas, textos com o título "curiosidade", como é o caso da fórmula } \\
\text { da clorofila ou da reação de Hill. Apresenta também a } \\
\text { representação do ciclo das pentoses. }\end{array}$ \\
\hline L2 - 1993 & $x$ & $\begin{array}{l}\text { O livro apresenta imagens de microscopia eletrônica da } \\
\text { estrutura das células vegetais e do cloroplasto. E utiliza gráficos } \\
\text { para representar a influência da luz. }\end{array}$ \\
\hline L3 - 1998 & $\mathrm{X}$ & $\begin{array}{l}\text { Apresenta diversas figuras e ilustrações acerca da estrutura } \\
\text { dos cloroplastos, de experimentos realizados ao longo dos anos e } \\
\text { da representação da fotossíntese. }\end{array}$ \\
\hline L4 - 1999 & $\bar{x}$ & $\begin{array}{l}\text { Apresenta imagens ilustrativas para representar a estrutura } \\
\text { dos cloroplastos, a experiência de Engelmann, representações dos } \\
\text { ciclos, tanto a fotofosforilação cíclica como a acíclica. Bem como } \\
\text { gráficos para mostrar os espectros de absorção da luz pela clorofila. }\end{array}$ \\
\hline
\end{tabular}




\begin{tabular}{|c|c|c|}
\hline L5 - 2001 & $X$ & $\begin{array}{l}\text { O livro apresenta várias ilustrações que representam a } \\
\text { hipótese heterotrófica e, também, o ciclo de como os produtos } \\
\text { formados por meio da fotossíntese podem ser utilizados como } \\
\text { reagentes, e vice-versa. Ademais, o livro apresenta gráficos para } \\
\text { explicar as ondas luminosas e a influência dessas. }\end{array}$ \\
\hline L6 - 2003 & $\bar{X}$ & $\begin{array}{l}\text { O livro traz diversas ilustrações a respeito da origem e } \\
\text { estrutura dos cloroplastos, apresentando o esquema da cadeia de } \\
\text { transporte de elétronse do ciclo de Calvin-Benson. }\end{array}$ \\
\hline L7 - 2009 & $X$ & $\begin{array}{l}\text { Apresenta ilustrações representativas da estrutura do } \\
\text { cloroplasto, os principais ciclos, e gráficos em relação à intensidade } \\
\text { de luz. }\end{array}$ \\
\hline L8 - 2013 & $X$ & $\begin{array}{l}\text { Ao iniciar o capítulo, o livro apresenta uma imagem de } \\
\text { plantação de milho com o objetivo de chamar a atenção dos alunos } \\
\text { no que diz respeito à fotossíntese; traz esquemas ilustrativos da } \\
\text { adenosina trifosfato (ATP), da cadeia de transporte de elétrons que } \\
\text { mostram a bicamada lipídica da membrana do tilacoide, bem como } \\
\text { as proteínas carregadoras de elétrons. O livro apresenta um } \\
\text { esquema do ciclo de Calvin - Benson, e desenhos ilustrativos da } \\
\text { anatomia e morfologia vegetal, e representa a planta em si, um } \\
\text { corte de folha, como são as células vegetais, os cloroplastos, as } \\
\text { granas em corte, a membrana do tilacóide e, por fim, a } \\
\text { representação da molécula de clorofila. }\end{array}$ \\
\hline
\end{tabular}

Em relação às criações didáticas, é possível perceber que os livros da década de 1990, ainda que apresentem esquemas e ilustrações, as trazem geralmente de maneira simplificada, e utilizam uma ou duas cores. Os livros após o período de 2000, detalham os processos por meio de esquemas elaborados e coloridos.

Em relação antigo/novo, o quadro 7 demonstra se o livro citou ou não os estudos realizados por Niel na década de 1930 nos quais percebeu que o $\mathrm{O}_{2}$ liberado pelas plantas era derivado da $\mathrm{H}_{2} \mathrm{O}$ e não do $\mathrm{CO}_{2}$ como se acreditava até o momento. O quadro na sequência (quadro 8) mostra se o livro apresenta ou não os conceitos de fotossíntese aceitos ao longo da história e se o conceito atual é abordado.

\section{Quadro 7 -}

Análise da relação antigo/novo "a"

\begin{tabular}{|c|c|c|c|}
\hline Livro & $\begin{array}{ll}\text { mão } & \\
\text { Nai } & \end{array}$ & & Descrição \\
\hline L1 - 1991 & $\mathrm{X}$ & são & $\begin{array}{l}\text { O livro relata que, após a fotólise da água, os hidrogênios } \\
\text { captados pela nicotinamida adenina dinucleotído fosfato }\end{array}$ \\
\hline
\end{tabular}




\begin{tabular}{|c|c|c|}
\hline & & $\begin{array}{l}\text { (NADP), já os oxigênios de doze moléculas de água se agrupam de } \\
\text { dois em dois, formando seis moléculas de } \mathrm{O}_{2} \text {. }\end{array}$ \\
\hline L2 - 1993 & & 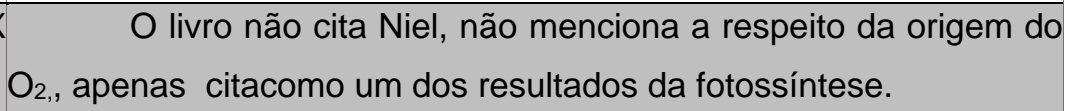 \\
\hline L3 - 1998 & & $\begin{array}{l}\text { O livro cita os estudos, porém não cita Niel. A obra } \\
\text { menciona sobre o pesquisador Hill em 1937, o qual realizou um } \\
\text { experimento obtendo oxigênio, com o uso de cloroplastos na } \\
\text { ausência de dióxido de carbono. }\end{array}$ \\
\hline L4 - 1999 & $\mathrm{X}$ & $\begin{array}{l}\text { Não cita Niel, mas o livro destaca diversas vezes que } 0^{\circ} \mathrm{O}_{2} \\
\text { liberado na atmosfera durante a fotossíntese é proveniente da água } \\
\text { que foi fotolisada. }\end{array}$ \\
\hline L5-2001 & $\bar{X}$ & $\begin{array}{l}\text { Não cita Niel, o livro apenas destaca diversas vezes que o } \\
\text { produto da fotossíntese se dá por meio da reação de moléculas de } \\
\text { água e gás carbônico, o que forma moléculas orgânicas e } \mathrm{O}_{2} \text {. }\end{array}$ \\
\hline L6 - 2003 & $\mathrm{X}$ & $\begin{array}{l}\text { O livro destaca que a quebra da água libera os oxigênios, } \\
\text { os quais se unem para formar a molécula de } \mathrm{O}_{2} \text {. }\end{array}$ \\
\hline L7 - 2009 & $\bar{X}$ & $\begin{array}{l}\text { Não cita Niel, porém o livro relata que a fonte exclusiva do } \\
\text { oxigênio liberado é a água. }\end{array}$ \\
\hline L8 -2013 & $\bar{X}$ & $\begin{array}{l}\text { O livro não cita a descoberta feita por Niel, entretanto } \\
\text { ressalta como ocorre o processo da fotólise da água e que o } \\
\text { oxigênio liberado provém diretamente das moléculas de água, } \\
\text { citando a reação de Hill. }\end{array}$ \\
\hline
\end{tabular}

\section{Quadro 8 -}

Análise da relação antigo/novo "b"

\begin{tabular}{|c|c|}
\hline Livro & \multicolumn{1}{c|}{ Descrição } \\
\hline L1-1991 & $\begin{array}{c}\text { Apresenta apenas o conceito atual no qual a fotossíntese é um processo } \\
\text { que ocorre no interior dos cloroplastos, sendo sua reação a síntese de glicose e } \\
\text { oxigênio molecular a partir de substâncias inorgânicas, água e gás carbônico. }\end{array}$ \\
\hline L2-1993 & $\begin{array}{l}\text { Não apresenta os principais acontecimentos históricos, relaciona a } \\
\text { fotossíntese apenas a um processo de fundamental importância para a vida } \\
\text { heterotrófica sendo responsável pela liberação de O }{ }_{2} \text { e matéria orgânica. }\end{array}$ \\
\hline L3-1998 & $\begin{array}{l}\text { Não cita os principais acontecimentos históricos, traz o conceito de } \\
\text { fotossíntese como a principal fonte de matéria orgânica para os seres vivos, além } \\
\text { de ser o processo responsável pelo fornecimento de oxigênio à atmosfera. }\end{array}$ \\
\hline L4-1999 & $\begin{array}{l}\text { Aborda apenas o conceito atual, em que o organismo fotossintetizante é } \\
\text { capaz de fazer a síntese de material orgânico a partir de substâncias } \\
\text { inorgânicas, com o uso de energia obtida por meio da luz. }\end{array}$ \\
\hline
\end{tabular}




\begin{tabular}{|c|c|c|}
\hline L5-2001 & $\begin{array}{l}\text { O livro não relata os conceitos de fotossíntese aceitos ao longo da } \\
\text { história, apenas cita a hipótese heterotrófica. Aborda o conceito atual de } \\
\text { fotossíntese de forma sucinta, descreve que é apenas um processo que captura } \\
\text { energia luminosa e converte em energia química, reunindo moléculas de } \mathrm{H}_{2} \mathrm{O} \text { e } \\
\mathrm{CO}_{2} .\end{array}$ \\
\hline L6-2003 & $\begin{array}{l}\text { Não apresenta os conceitos desenvolvidos ao longo da história, traz o } \\
\text { conceito atual de fotossíntes e como um processo pelo qual moléculas de gás } \\
\text { carbônico e de água se combinam quimicamente por meio de energia luminosa } \\
\text { para formar moléculas orgânicas e moléculas de gás oxigênio. }\end{array}$ \\
\hline L7-2009 cita os principais conceitos desenvolvidos ao longo dos anos, \\
$\begin{array}{l}\text { porém traz como conceito de fotossíntese um processo responsável pela } \\
\text { absorção de luz e transformação de gás carbônico e água em açúcares, as quais } \\
\text { a planta utiliza para produzir todas as substâncias orgânicas que formam seu } \\
\text { corpo, além de ser um processo responsável pela produção de oxigênio. }\end{array}$ \\
\hline $\begin{array}{l}\text { Não cita as descobertas desenvolvidas ao longo dos anos, traz o } \\
\text { conceito de fotossíntese como uma conversão da energia luminosa em energia } \\
\text { química nas substâncias orgânicas. }\end{array}$
\end{tabular}

O livro L2 - 1993 não citou os estudos realizados por Niel na década de 1930, apenas relata que o oxigênio liberado pelas plantas é um produto da fotossíntese, sem dar detalhes de sua origem. A falta de uma explicação como essa pode levar os alunos a relacionarem a origem dessa molécula ao gás carbônico, e não a água como se acreditava anteriormente. Os demais livros, embora mencionem o experimento e a origem do oxigênio proposta por Niel, não o citam, apenas apontam o pesquisador Hill, que por meio de seus experimentos colaborou muito para corroborar a proposta de Niel.

Nenhum dos livros analisados deu enfoque ao processo de desenvolvimento do conceito de fotossíntese, embora todos eles abordem o conceito aceito atualmente. Os livros L2 - 1993 e L3 1998 apresentaram o conceito atual de maneira simplificada, enfatizando a importância na vida heterotrófica.

Quanto ao envelhecimento moral/biológico, o quadro 9 descreve na coluna "a" se os conteúdos foram renovados ao longo da história de modo a acompanhar os avanços sociais; e na coluna "b" se o livro apresenta a importância do conteúdo para a vida do aluno.

\section{Quadro 9-}

Análise do envelhecimento moral/biológico

\begin{tabular}{|l|rrrr}
\hline Livro & \multicolumn{1}{c}{ VIII (a) } & \multicolumn{1}{c}{ VIII (b) } \\
\hline L1 - 1991 & \multicolumn{2}{|c}{ Relata a origem do oxigênio liberado } & Aborda que é por meio \\
& e como ele é formado por meio da reação dedesse & processo & que & os \\
& Hill. & organismos & heterotróficos \\
& & conseguem a energia e matéria \\
\hline
\end{tabular}




\begin{tabular}{|c|c|}
\hline & $\begin{array}{l}\text { orgânica necessária } \\
\text { sobreviverem. }\end{array}$ \\
\hline L2 - 1993 & 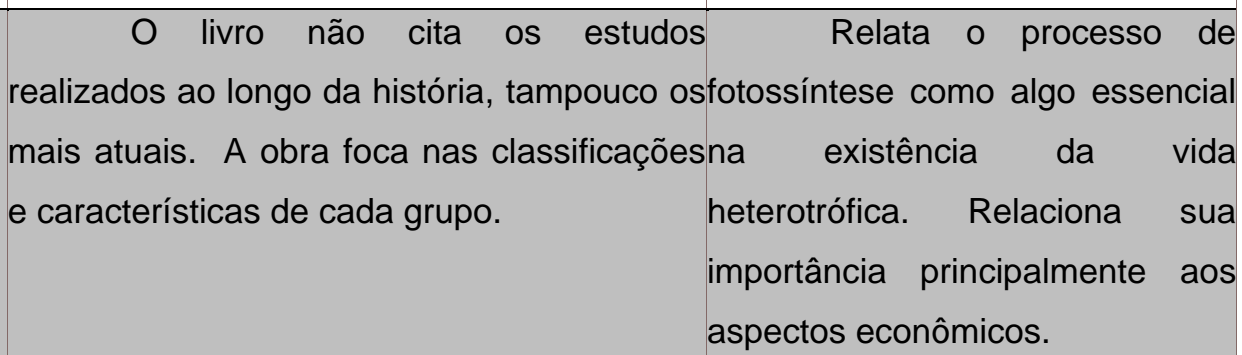 \\
\hline L3 - 1998 & $\begin{array}{l}\text { Não cita nenhum autor e os estudos } \\
\text { realizados, porém apresenta os conceitosfotossíntese é importante para a } \\
\text { atuais. Cita, por exemplo, o ciclo dasprodução do oxigênio presente na } \\
\text { pentoses ou ciclo de Calvin, bem como aatmosfera, o qual é utilizado na } \\
\text { utilização do NADPH2, e ATP durante orespiração dos seres heterótrofos, } \\
\text { processo. Apresenta, também, algunsgerando para eles também } \\
\text { experimentos importantes realizados nomatéria orgânica utilizada em seu } \\
\text { processo de construção do conceito. }\end{array}$ \\
\hline 999 & $\begin{array}{l}\text { O livro destaca algumas substâncias } \\
\text { responsáveis pelo transporte de elétrons,fotossíntese é um processo que } \\
\text { como a ferredoxina e os citocromos.dá origem a um dos principais } \\
\text { Apresenta a diferenciação da clorofila a e b,produtos para vida dos seres. } \\
\text { bem como os ciclos de fotofosforilação } \\
\text { cíclico e acíclico. Aborda que, depois da } \\
\text { fotólise da água, os prótons oriundos dos } \\
\text { átomos de hidrogênio são entregues à } \\
\text { NADP reduzido, o qual recebendo dois } \\
\text { prótons passa a ser NADPH2. Cita também } \\
\text { as principais substâncias responsáveis pelo } \\
\text { ciclo das pentoses de Calvin, como a } \\
\text { ribulose-1 e o6-difosfato. Aborda também os } \\
\text { experimentos realizados em relação à } \\
\text { intensidade e ondas luminosas, } \\
\text { evidenciando os espectros de luzes. }\end{array}$ \\
\hline L5 - 2001 & 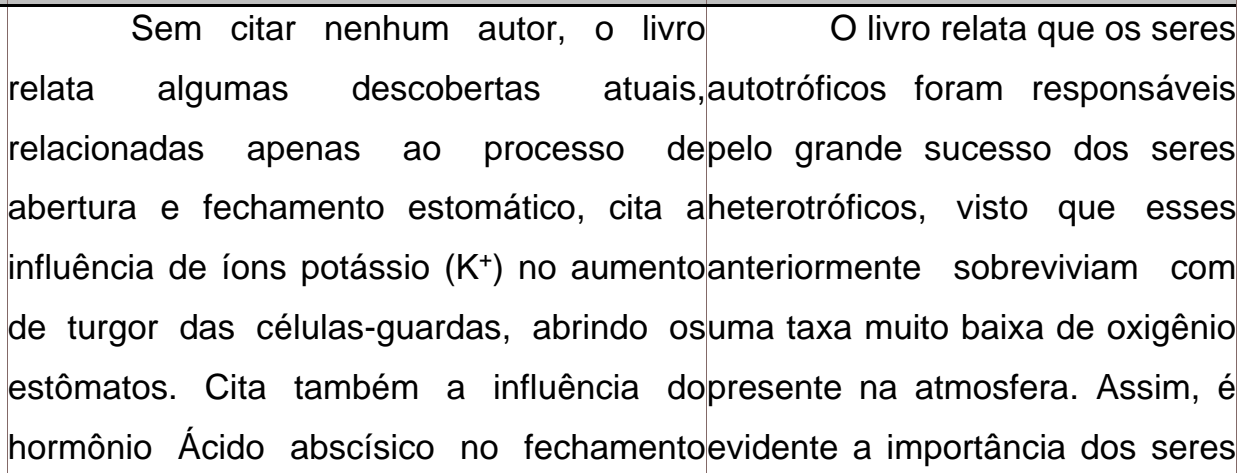 \\
\hline
\end{tabular}




\begin{tabular}{|c|c|}
\hline & $\begin{array}{l}\text { dos estômatos em baixas quantidades defotossintetizantes para os demais } \\
\text { água. Não cita nenhuma descoberta atualseres. } \\
\text { sobre o processo de fotossíntese de fato. }\end{array}$ \\
\hline L6 - 2003 & $\begin{array}{l}\text { Não apresenta citações dos estudos Não } \text { apresenta a } \\
\text { desenvolvidos, apresenta conceitos atuais,importância do conteúdo para a } \\
\text { como o Ciclo de Calvin-Benson. Citavida dos alunos. } \\
\text { também os compostos intermediários } \\
\text { formados, como a RuBP e PGA. }\end{array}$ \\
\hline L7- 2009 & $\begin{array}{l}\text { Embora não exista uma citação dos } \quad \text { O livro destaca a } \\
\text { estudos desenvolvidos ao longo dos anos, oimportância do conteúdo para a } \\
\text { livro acompanhou a história e apresentavida do aluno como um processo } \\
\text { conceitos bem atuais, embora ainda abordeessencial para a nutrição e } \\
\text { as fases da fotossíntese como fase clara erespiração dos indivíduos } \\
\text { fase escura, quando hoje em dia essesheterotróficos. } \\
\text { conceitos não são mais utilizados, pois são } \\
\text { abordados como fase fotoquímica e } \\
\text { bioquímica da fotossíntese. }\end{array}$ \\
\hline L8 - 2013 & $\begin{array}{l}\text { O livro não faz uma relação das } \\
\text { descobertas que fizeram parte do conceitoé um importante processo na } \\
\text { histórico com o atual, apenas aborda osconversão de energia luminosa } \\
\text { estudos levantados por Van Helmont e Niel,em energia química, e que essa é } \\
\text { sem apresentar os avanços históricos.a qual supre o metabolismo de } \\
\begin{array}{l}\text { Aborda também sobre a cadeia depraticamente todos os seres } \\
\text { transporte de elétrons, a redução do NADPvivos. Atribui também uma } \\
\text { em NADPH, fotólise da água e relata sobre oimportância econômica ao } \\
\text { ciclo de Calvin-Benson. } \\
\text { caracterizar o crescimento vegetal } \\
\text { principalmente pela água, o que , } \\
\text { hoje em dia, é possível realizar o } \\
\text { processo de hidropônica. }\end{array}\end{array}$ \\
\hline
\end{tabular}

Em relação à renovação dos conceitos ao longo dos estudos analisados, em geral, os livros relatam sobre o estudo realizado por Niel e Hill na década de 1930, e citam ou não um desses pesquisadores. Isso, pois acredita-se tratar de um dos estudos mais importantes no processo de formação do conceito de fotossíntese. Em relação aos demais avanços existentes, os LD citam um ou outro autor, embora não abordem todos ou os principais estudos, evidencia-se a despersonalização. Ainda que seja evidente a importância de trabalhar a história da Ciência em sala de aula, a despersonalização se faz necessária no processo de transposição didática.

Com exceção do livro de 2003, todos os livros apresentaram a importância do processo de fotossíntese dando ênfase a sua importância para o grande sucesso e sobrevivência dos seres 
heterotróficos. Apenas os livros de 1993 e 2003 apresentam brevemente uma importância econômica voltada para esse processo.

\section{Considerações finais}

Alguns dos livros analisados não relacionam o conteúdo a uma problemática da época, abordamapenas os estudos realizados pelos cientistas ao longo dos anos. Isso retrata um problema, pois o aluno necessita de um ensino que o prepare para a vida, e que forneça atributos que possibilitem o desenvolvimento de sua criticidade.

Em relação ao ensino e aprendizagem, acredita-se ser indispensável o conhecimento histórico para que o aluno compreenda que todo aprendizado em sala de aula foi construído, por issofaz-se necessária a citação dos autores ou dos estudos realizados duranteo período de construção do conceito de fotossíntese aceito atualmente pela comunidade científica.

Por meio da análise do fato de que a origem do oxigênio liberado durante a fotossíntese ainda é uma das mais divergentes explicadas pelos alunos, abordar os estudos realizados por Hill e Niel, os quais detalham que o oxigênio liberado provém da molécula de água e não do gás carbônico como se acreditava, são extremamente indispensáveis.

Outro fator importante é que, no geral, todos os livros que apresentaram o conceito de fotossíntese vincularam esse processo apenas ao sustento da vida heterotrófica, sem abordar a real importância desse para a sobrevivência dos indivíduos autotróficos. Assim, o processo torna-se apenas existente para a formação de nutrientes responsáveis pela manutenção da vida heterotrófica.

Em pesquisas anteriores, pôde-se visualizar uma demora na transposição didática do conceito de fotossíntese. Porém, essa pesquisa revelou que, no geral, os livros datados entre 1990 a 2015 trazem os conceitos aceitos pela comunidade científica. É visível uma simplificação dos LD de tal forma que, para que o ensino não seja defasado, os professores devem pesquisar sobre as novas contribuições da ciência e repassá-las a seus alunos. Cabetambém ao professor realizar a vigilância epistemológica, pois, devido às transformações do saber, pode haver futuros conceitos errôneos nos $L D$, visto que o conhecimento está em constante (re)construção.

Após a análise dos elementos da transposição didática presentes nesses livros, pode-se dizer que nenhum seguiu todos os parâmetros para a transformação do saber com o objetivo de torná-lo mais compreensível ao aluno. Além disso, fica evidente que os LD distribuídos para a rede pública de ensino não poderiam ser utilizados pelos professores como fonte única de consulta para a elaboração de suas aulas. Entretanto, por meio dos resultados obtidos, foi possível visualizar também que, com o passar dos anos, os LD têm apresentado uma melhora significativa em relação à transposição didática, pois são mais coerentes, principalmente no que diz respeito à descontextualização e a despersonalização.

\section{Referências bibliográficas}

Almeida, R. O. (2005). Noção de fotossíntese: obstáculos epistemológicos na construção do conceito científico atual e implicações para a educação em ciência. Revista Virtual, 1 (1). 
Bachelard, G.. A (1996). Formação do espírito científico: Contribuição para uma psicanálise do conhecimento. Rio de Janeiro: Contraponto.

Brasil. Ministério da Educação. Secretaria da Educação Média e Tecnológica (2002). Parâmetros Curriculares Nacionais do Ensino Médio (PCNEM) - Ciências da Natureza, Matemática e suas Tecnologias. Brasília: MEC, Disponible en: http://portal.mec.gov.br/seb/arquivos/pdf/ciencian.pdf. Consultada el: 30 de abril de 2016.

Carvalho, A. (2004). Construção do conhecimento e ensino de ciências. Em Aberto, v. 11, n. 55, 1992.

Flick, U. Introdução à pesquisa qualitativa. 2. ed. Porto Alegre: Artmed.

Chevallard, Y. (1991). La transposición didáctica: del saber sabio al saber enseñado. Buenos Aires: Aique Grupo Editor S. A.

Gomes, O. C., Gomes, S.R, Terán, A.F . A (2014). Transposição Didática: Diálogos Em Escola De Manaus/AM. DIÁL. In: IV Simpósio Em Educação Em Ciências Na Amazônia, 2014, Manaus. IV Simpósio Em Educação Em Ciências Na Amazônia, v. 1, p. 1-12.

Martins, I. (2006). Analisando livros didáticos na perspectiva dos Estudos do Discurso: compartilhando reflexões e sugerindo uma agenda para a pesquisa. Pro-Posições. Vol (17): 117-136.

Melzer, E. E. M. (2012). Do Saber Sábio ao Saber a Ensinar: A Transposição Didática do Conteúdo Modelo Atômico de Livros de Química (1931 - 2012). Dissertação, Universidade Federal do Paraná, Curitiba.

Neves, K. C. R. (2009). Um Exemplo de Transposição Didática: o caso das Matrizes. Dissertação de Mestrado, Programa de Pós-Graduação em Educação para a Ciência e a Matemática do Centro de Ciências Exatas, Universidade Estadual de Maringá.

Rodrigues, M. E., Justina, L. A. D., Meglhioratti, F. A. (2011). O conteúdo de sistemática e filogenética em livros didáticos do ensino médio. Ensaio, v.13, n.02, p.65-84.

Santos, N. Q., Schneider, E. M., Justina, I. A. D. (2019). Obstáculos epistemológicos sobre a água em livros didáticos de ciências do sexto ano do ensino fundamental, no PNLD 2017 do Brasil. GÓNDOLA, ENSEÑANZA Y APRENDIZAJE DE LAS CIENCIAS, v. 14, p. 376-391, 2019. Diponível em: file:///sysroot/home/lourdes/Downloads/DialnetObstaculosEpistemologicosSobreAAguaEmLivrosDidatic-7041223.pdf. Acesso: 20 de março de 2020.

Souza, S. C., Almeida, M. J. P. M. (2002). A fotossíntese no ensino fundamental: compreendendo as interpretações dos alunos. Ciência \& Educação. Vol (8): 97-111. 